\title{
Soberania E Justiça EM Rousseau
}

\author{
Thomaz Kawauche ${ }^{1}$
}

RESUMO: Trata-se, neste artigo, de discutir a novidade introduzida por Rousseau em relação à noção moderna de soberania, que tem Bodin como representante fundador. A análise toma por objeto a relação entre soberania e leis civis, a qual é compreendida nos termos da oposiçáo, encontrada no Contrato social, entre justiça natural e justiça civil.

PALAVRAS-CHAVE: Soberania. Justiça. Lei. Política. Religião.

A ideia de que o soberano deve estar acima da lei, no sentido de possuir o poder para criar e alterar as leis civis segundo sua vontade, aparece pela primeira vez de modo conceitual em Jean Bodin. Na República (I, 8), lemos: "É preciso que os soberanos possam dar a lei aos súditos e anular ou revogar as leis inúteis para fazer outras; o que não pode ser feito por aquele que está submetido às leis ou por aquele que está sob o comando de outrem." (apud BARROS, 2001, p. 237). Tal afirmação pressupóe uma distinção entre quem manda e quem obedece e, nesses termos, a obrigaçáo implica em alteridade: a obediência é devida à lei que um outro estabelece, visto que ninguém pode se obrigar a si mesmo. ${ }^{2}$ Nas palavras de Bodin, ainda na República (I, 8):

Se o príncipe soberano está isento das leis dos seus predecessores, muito menos estará preso às leis e ordenanças que faz, uma vez que se pode receber a lei de outrem, mas é impossível por natureza dar-se uma lei, não mais que comandar a si mesmo, coisa que depende de sua vontade. (apud BARROS, 2001, p. 239).

\footnotetext{
${ }^{1}$ Doutor em Filosofia pela USP e pesquisador de pós-doutorado da FAPESP. E-mail: kawauche@ gmail.com

${ }^{2}$ Evitamos aqui o termo "heteronomia", em oposição a "autonomia", que Kant utiliza na Fundamentação da metafísica dos costumes (1785), pois o registro da discussão do texto kantiano é mais voltado para a moral do que para a política e, além disso, o conceito de "alteridade" nos parece muito mais interessante para analisarmos a relação entre a função do legislador e a soberania do povo em Rousseau, como o leitor poderá perceber ao final deste artigo.
} 
Quase dois séculos mais tarde, Rousseau introduz a noção de soberania popular baseando-se em um princípio que, de certa forma, subverte o conceito primevo de soberania estabelecido por Bodin: "O povo, submetido às leis, deve ser o autor delas" (O.C. III, p. 380). ${ }^{3}$ A novidade implicada na frase reside não tanto na noção de povo soberano - que já aparecia nas teorias democráticas da escola do direito natural (cf. DERATHÉ, 2009, p. 87-88) -, mas muito mais na ideia paradoxal de um soberano que cria leis às quais ele mesmo deve se submeter. Náo por acaso, trata-se da ideia central do pacto rousseauniano, expressa na condição de que "[...] cada um, unindo-se a todos, só obedeça, contudo, a si mesmo” (O.C. III, p. 360). Em uma palavra, o que Rousseau defende no Contrato social é que a legitimidade da soberania do povo para o estabelecimento das leis não é apenas uma questão jurídico-política (i.e., com coerção externa), mas também moral (i.e., dependente da vontade dos indivíduos): "[...] somente aos que se associam compete regulamentar as condições da sociedade” (O.C. III, p. 380).

Neste artigo, queremos discutir a seguinte tese: na relaçáa entre soberania e leis civis, a novidade introduzida por Rousseau quanto à noção moderna de soberania, que tem Bodin como representante fundador, pode ser compreendida com base na oposição entre justiça natural e justiça civil encontrada no Contrato social. O que segue é uma tentativa de mostrar como uma análise que tem por objeto a relação entre religião e política em Rousseau pode ajudar a esclarecer algumas questôes de terminologia na história do pensamento político.

Em primeiro lugar, é preciso assinalar que a definição de justiça para Rousseau está mais ligada a uma garantia de que todos vão obedecer às leis civis do que à noção mais usual de justiça distributiva, a saber, dar a cada um o que lhe é devido, que remonta a Platão (cf. VILLEY, 2005; KELSEN, 2000). $\mathrm{E}$, de fato, nas Cartas escritas da montanha (carta IX), podemos perceber que Rousseau associa a justiça àquela condição de igualdade moral - isto é, de obrigaçóes mútuas - promovida pelo pacto:

O primeiro e maior interesse público é sempre a justiça. Todos querem que as condiçóes sejam iguais para todos e a justiça náo é senão esta igualdade. $\mathrm{O}$ cidadão não quer senão as leis, e só a observação das leis. Cada particular no povo sabe bem que se houver exceçóes, elas não serão

\footnotetext{
${ }^{3}$ As citaçôes de Rousseau remetem o leitor às Oeuvres Complètes de Jean-Jacques Rousseau (O.C.), indicando-se o volume da coleçấo e a página. As traduçôes brasileiras adotadas são aquelas listadas na bibliografia.
} 
a seu favor. Assim, todos temem as exceçóes, e quem teme as exceções ama a lei. (O.C. III, p. 891).

Esse ponto já indica um certo deslocamento em relação ao registro tradicional das discussóes sobre a justiça, aproximando-se da ideia de "igualdade perante a lei", que Hans Kelsen (1993, p. 59-60) distingue da "igualdade na lei”, em sua teoria pura da justiça. Percebe-se daí que o que está em jogo é uma concepção mais prática do que teórica da justiça, pois, na passagem acima, nosso autor pensa não em leis que afirmem, em seu conteúdo, a igualdade entre todos os homens, mas em leis já instituídas, bem como na aplicação delas no seio de sociedades marcadas pela desigualdade. No entanto, sem entrarmos no debate jurídico tal como Kelsen o faz, queremos apenas sugerir aqui que a inovação de Rousseau pode ser mais bem apreciada por meio do esquema de oposiçóes entre justiça natural e justiça civil, apresentado em um parágrafo no capítulo 6 do segundo livro do Contrato social:

O que é bom e conforme à ordem o é pela natureza das coisas e independente das convençóes humanas. Toda justiça provém de Deus, só ele é a sua fonte; mas, se soubéssemos recebê-la de tão alto, não necessitaríamos nem de governo nem de leis. Há, por certo, uma justiça universal que emana unicamente da razáo, porém essa justiça, para ser admitida entre nós, precisa ser recíproca. Se consideramos humanamente as coisas, desprovidas de sançáo natural, as leis da justiça são vãs entre os homens. Produzem somente o bem do malvado e o mal do justo, quando este as observa para com todos sem que ninguém as observe para com ele. Por conseguinte, tornam-se necessárias convençóes e leis para unir os direitos aos deveres e conduzir a justiça a seu fim. No estado de natureza, em que tudo é comum, nada devo àqueles a quem nada prometi, e náo reconheço como de outrem senão o que me é inútil. $\mathrm{O}$ mesmo nâo se passa no estado civil, no qual todos os direitos são estabelecidos pela lei. (O.C. III, p. 378).

De modo geral, a importância desse parágrafo reside no fato de ele mostrar que a necessidade da justiça deriva da necessidade de leis, o que está de acordo com a opiniáo de Rousseau - expressa já no Manuscrito de Genebra (O.C. III, p. 329) - quanto à anterioridade da lei em relação à justiça, e náo o inverso, como defendiam, por exemplo, Bossuet e Filmer (cf. GOLDSCHMIDT, 1974, p. 637-638). Para nossa leitura, é preciso observar, antes de tudo, que lei e justiça são discutidas a partir da distinção entre o "estado de natureza" e o "estado civil", que Rousseau estabelece como armação 
lógico-conceitual para poder desenvolver sua análise: de um lado, um estado “em que tudo é comum" pela total ausência de acordos ("nada devo àqueles a quem nada prometi”); de outro lado, um estado de direitos, isto é, uma ordem instituída que, para se manter, depende do cumprimento de acordos entre os homens. A essa distinção entre natureza e sociedade se sobrepóe uma segunda, entre a justiça natural e a justiça humana: de um lado, "uma justiça universal que emana unicamente da razão", associada à "ordem" e à "natureza das coisas"; de outro, uma justiça fundada em "convençóes humanas", a saber, "governo", "leis", "direitos" e "deveres".

Notemos que a passagem em questão se situa no contexto da busca pelo fundamento legítimo da ordem civil; mais especificamente, no momento da démarche do Contrato em que Rousseau trata da legislação. Não por acaso, o capítulo em que se encontra a passagem intitula-se "Da lei". Devemos atentar ainda para a importância que a questão do poder adquire na passagem: a justiça natural é mantida por um poder proveniente da natureza - Rousseau fala em uma "sanção natural". Logo, se a pergunta que se coloca no plano geral do Contrato diz respeito à legitimidade da ordem civil, então, no contexto da passagem estudada, essa legitimidade pode ser entendida como a do poder que garante a manutençáo da justiça entre os homens.

O parágrafo todo gira em torno da imagem teológico-política do deus que legisla e governa sobre a natureza: “Toda justiça provém de Deus, só ele é a sua fonte". Ora, se Deus é a fonte de legitimidade absoluta (pois toda justiça provém de Deus), a justiça natural, mantida pelo poder divino, torna-se entáo a referência para que se possa julgar a legitimidade da justiça dos homens. Contudo, é importante observar uma diferença fundamental que surge a partir desse quadro comparativo: a justiça dos homens está baseada em convençóes, o que a torna uma justiça condicionada ao arbítrio humano. Por conseguinte, a ordem civil, diferentemente da ordem da natureza, necessita de mecanismos que garantam sua manutenção, dado que o homem é livre para cumprir ou náo seus deveres nos acordos estabelecidos. Pois, como explica Rousseau nas Cartas escritas da montanha (carta VIII), sem uma conformação das liberdades individuais às leis estabelecidas, não é possível haver sociedade: "[...] a liberdade sem a justiça é uma verdadeira contradição, pois, não importa o que se pense, tudo constrange na execução de uma vontade desordenada" (O.C. III, p. 372).

Devemos ressalvar que o problema da fragilidade da ordem civil não é a ausência de deveres universais, porque eles aparecem, por exemplo, na fórmula "Faze a outrem o que desejas que façam a ti", que Rousseau chama de "máxima 
sublime da justiça raciocinada", no Discurso sobre a desigualdade (O.C. III, p. 156). O problema está na existência de direitos particulares que acabam tornando desvantajosa a reciprocidade no reconhecimento dos direitos de outrem. $\mathrm{Na}$ falta de um poder civil que assegure a reciprocidade dos acordos, as leis da justiça "são vãs entre os homens", visto que só promovem "o bem do malvado e o mal do justo", em vez do bem comum. Perceba-se, portanto, que é precisamente esse hiato entre direitos e deveres que torna necessária a instituição de um substituto para a "sanção natural" na tarefa da conservação da sociedade, a saber, o binômio formado pelo "governo" (que é o poder executivo) e pelas "leis" (com base nas quais o governo age). Podemos entáo entender que, quando Rousseau escreve "tornam-se necessárias convenções e leis para unir os direitos aos deveres e conduzir a justiça ao seu fim", ele quer simplesmente afirmar a necessidade do poder executivo - que é o equivalente civil da "sançấo natural" - para garantir a reciprocidade nos acordos entre os homens, isto é, a justiça no estado civil. Afinal, é tão-somente essa reciprocidade que garante o caráter obrigatório dos compromissos no Contrato: "Os compromissos que nos ligam ao corpo social só são obrigatórios por serem mútuos” (O.C. III, p. 373).

Todavia, há no texto em questão uma frase muito importante, que, por indicar a perspectiva de Rousseau, é decisiva em nossa análise: "Se consideramos humanamente as coisas..." Palavras fundamentais: nosso autor considera as coisas "humanamente", isto é, em oposição à perspectiva divina, que corresponderia ao conhecimento absoluto das coisas. Isso implica dizer que Rousseau reconhece, como o vigário saboiano, a "[...] insuficiência do espírito humano" (O.C. IV, p. 568) no conhecimento da ordem natural. Porém, assim como ocorre com o vigário, essa limitaçáo da faculdade cognitiva não chega a ser um problema, visto que Rousseau está menos preocupado com as "[...] luzes sobrenaturais" (O.C. IV, p. 608) do que com aquele conhecimento "[...] útil para a prática" (O.C. IV, p. 570). Tanto é assim que ele não apenas nega toda e qualquer intervenção da divindade nos negócios humanos (as leis da justiça são "desprovidas de sanção natural"), como também admite a impossibilidade de se reproduzir os mecanismos da natureza na ordem civil, em especial, a justiça natural ("se soubéssemos recebê-la de tão alto..."). A solução prática consiste em instituir racionalmente uma justiça civil e considerá-la, por hipótese, equivalente à justiça natural, ainda que essa instituição não necessariamente reproduza (como ter certeza?) os mesmos mecanismos da justiça universal. 
De qualquer maneira, na comparação entre a ação divina e a ação humana, Rousseau considera suficiente saber que o paralelo pode ser estabelecido apenas com base no princípio racional da ordem do universo, sendo totalmente irrelevante a falta de conhecimento dos detalhes dessa ordem: "Julgo a ordem do mundo embora desconheça seu fim, porque para julgar essa ordem basta-me comparar as partes entre si, estudar seu concurso, suas relaçóes, observar seu concerto" (O.C. IV, p. 578). "Que me importa?”, é a pergunta mais conveniente ao sábio, que, de acordo com a Profissão de fé do vigário saboiano, deve se prender às relaçôes imediatas e sensíveis (O.C. IV, p. 483). A relação entre justiça divina e justiça humana, no parágrafo em questão do Contrato, deve ser apreciada, por conseguinte, do ponto de vista estritamente político, e não teológico. De fato, mesmo que os homens possam se inspirar na justiça divina para instituírem a justiça humana, ainda assim aquilo que Rousseau denomina "justiça universal” (que no contexto da passagem pode ser entendido como justiça divina) não passa de uma hipótese criada pelos homens, que tentam explicar em termos da justiça humana os “[...] mistérios impenetráveis" (O.C. IV, p. 568) da realidade. Trata-se, antes de tudo, de um modelo. ${ }^{4}$

Se nos lembrarmos do artigo "Droit naturel et simulacre", de Patrick Hochart (1967), podemos afirmar que a relação entre justiça divina e justiça humana se exprime em termos de uma relação entre modelo e simulacro, na qual se verifica, de um lado, uma filiação do simulacro para com o modelo, e de outro, uma oposição do simulacro que luta contra o modelo (HOCHART, 1967, p. 81). O antagonismo das partes não anula a mutualidade entre elas e implica em uma relação na qual um termo reenvia ao outro reciprocamente. Nas palavras de Hochart:

\footnotetext{
${ }^{4} \mathrm{O}$ sentido da palavra "modelo" que usamos aqui é o mesmo que Rousseau utiliza no Contrato, quando se refere à família como "[...] o primeiro modelo das sociedades políticas" (O.C. III, p. 352). Parece-nos que o princípio segundo o qual esse "modelo" de Rousseau seria construído se encontra indicado no capítulo "Da sociedade geral do gênero humano", do Manuscrito de Genebra: "[...] é somente a partir da ordem estabelecida entre nós que temos as ideias daquela que imaginamos. Concebemos a sociedade geral a partir de nossas sociedades particulares, o estabelecimento das pequenas Repúblicas nos faz pensar na grande, e só começamos propriamente a nos tornar homens após ter sido Cidadãos." (O.C. III, p. 287). Outra passagem importante para ilustrar esse movimento encontra-se na Nova Heloísa (VI, 7), numa carta em que Saint-Preux se refere a um raciocínio por induçấo que vai do particular ao universal: "Sem querer entrar convosco em novas discussōes sobre a ordem do universo e sobre a direção dos seres que o compôem, contentar-me-ia em dizer-vos que, sobre essas questốes que estấo tắo acima do homem, ele não pode julgar as coisas que não vê senão por indução, a partir das que vê, e que todas as analogias referem-se a essas leis gerais que pareceis rejeitar." (O.C. II, p. 682-683). Nesse sentido, o "simulacro" que deriva do "modelo" seria nada mais do que aquilo que inspira o "modelo", ou seja, simulacro de simulacro. É nesses termos que parece funcionar a relaçáo entre justiça divina e justiça dos homens.
} 
Mas o simulacro não surgiu inocentemente para substituir um modelo originário que lhe seria preexistente e inexplicavelmente se ausentaria; é ele que destrói o modelo e é o mesmo movimento que abole o modelo e constitui o simulacro. Assim, a luta entre simulacro e modelo é originária (simul); ao mesmo tempo que o primeiro começou a desfigurar o segundo já o segundo é simulado pelo primeiro; nesse sentido, o modelo reenvia ao simulacro do mesmo modo como o simulacro ao modelo. (HOCHART, 1967, p. 82).

Devemos lembrar que, para efeito dos raciocínios de Rousseau, o modelo não precisa possuir realidade histórica, podendo ser considerado hipoteticamente na relação com seu simulacro. ${ }^{5}$ Além disso, não podemos esquecer que o modelo e o simulacro são sempre relativos um ao outro, e aquilo que é tomado por simulacro em uma relação pode ser considerado modelo em outra. ${ }^{6}$ Hochart explica que essa concepçáo de reciprocidade entre modelo e simulacro nos permite conhecer o duplo movimento do pensamento rousseauniano - por exemplo, aquele que diz respeito à relação entre sociedade geral e sociedade civil -, segundo o qual o modelo perfeito é restituído "fictivement", a partir do simulacro, para poder servir de fundamento a este, de modo que o simulacro é sempre "simulacro de simulacro". Hochart reconhece que esse tipo de relaçẫo no qual os termos se reenviam um ao outro resulta em um problema de indeterminação - o "estatuto vacilante" de um modelo que jamais deixa de ser "quimera" -, que só pode ser resolvido pela noção de "simulacro divino" (HOCHART, 1967, p. 82). Evidentemente, esse "recurso teológico" bem poderia ser considerado um retorno à teologia, por parte de Rousseau, mas acreditamos que não necessariamente, pois, como explica Hochart, trata-se tãosomente de garantir a "eficácia operatória" do conceito de "modelo fundamento" e, assim, assegurar um "verdadeiro estatuto" às noçôes de sociedade geral e direito natural (HOCHART, 1967, p. 83). Ou seja, trata-se de uma solução prática do problema, pois o que importa não é o modelo em si mesmo, mas, segundo

\footnotetext{
${ }^{5} \mathrm{O}$ tema da justiça divina na Profissáo de fé do vigário saboiano é ilustrativo aqui: mesmo admitindo ser incapaz de conhecer a natureza da justiça divina, nem por isso o vigário deixa de supor critérios de justiça para determinar o destino dos bons e dos maus. De acordo com seu método de investigaçáo, o vigário se refere a um "sentimento" de que a justiça divina funciona em conformidade à ordem da natureza, que, por sua vez, também inspira os critérios que regulam a justiça meritocrática dos homens: "Esse sentimento baseia-se menos no mérito do homem do que na noçáo de bondade que me parece inseparável da essência divina. Não faço mais do que supor que as leis da ordem sejam observadas e que Deus seja inflexível consigo mesmo." (O.C. IV, p. 591).

${ }^{6}$ A sociedade geral é o modelo, quando considerada na relação com a sociedade civil, mas a sociedade civil é modelo, quando considerada na relação com as associaçōes (cf. HOCHART, 1967, p. 81).
} 
Hochart, aquilo que se obtém por meio de seu funcionamento. Acusar Rousseau de teologismo em sua concepção de justiça natural seria o mesmo que dizer que o Contrato social é uma teologia-política, porque termina com o capítulo da religião civil, cujos dogmas ali enunciados cumprem a função de dar ao cidadáo uma esperança de justiça na vida futura.

Com base nesse esquema que separa uma instância natural associada à divindade e uma instância civil associada aos homens, podemos agora examinar o deslocamento operado por Rousseau, quanto à noção bodiniana de soberania. Em primeiro lugar, é preciso reconhecer que a noção de soberania popular do Cidadão de Genebra não vem abolir a alteridade na questão do estabelecimento das leis, visto que, mesmo sendo o povo o autor delas, é somente o legislador, com sua "inteligência superior" (O.C. III, p. 381), que consegue determinar a vontade geral do corpo político expressando-a em forma de um sistema de legislaçáo. A diferença em relaçáo ao conceito bodiniano de soberania é que Rousseau estabelece a distinção entre o legislador e o poder legislativo. Assim, o autor das leis é o povo, porque só os membros da associação detêm o poder legislativo, ainda que seja preciso haver um guia dotado de "razão sublime" capaz de despertar o "espírito social" na passagem do estado de natureza para o estado civil, fazendo com que a "multidão cega" consiga enxergar a necessidade do estabelecimento das leis (O.C. III, p. 380 e 383). Muito embora o povo seja conduzido por uma figura extraordinária que lembra legisladores religiosos, como Moisés ou Numa - pois o legislador é uma espécie de arauto da divindade -, a fonte de legitimidade do ato de instituir leis não é transcendente, de modo que, em última instância, a soberania permanece com o povo. Afirmar que " $[\mathrm{h}]$ averia necessidade de deuses para dar leis aos homens" (O.C. III, p. 381) não significa dizer que o outro a quem compete a tarefa da legislação é uma entidade sobre-humana, mas apenas, num sentido metafórico, que é preciso um nível diferenciado de consciência política do próprio povo, a fim de que as leis sejam instituídas. Com efeito, o autor das leis é, de direito, o próprio povo, porém, isso só se torna possível, de fato, com a intervenção de uma autoridade de "outra ordem", a do legislador, que faz os deuses falarem numa revelação imanente (O.C. III, p. 383-384): não se trata de um discurso teológico sobre as virtudes do reino dos céus, mas de um discurso político, sobre a conduta necessária para o estabelecimento de uma justiça puramente civil do ponto de vista da história. ${ }^{7}$

\footnotetext{
${ }^{7}$ Para uma análise do capítulo sobre o legislador, cf. KAWAUCHE, 2012, cap. 3. Na tese, mostro que Rousseau alterna sistematicamente entre dois pontos de vista distintos: o do direito político (o plano do dever-ser) e o da história (o plano concreto das coisas tais como são), porém, sem submeter nem
} 
Estando, pois, separadas a instância dos deuses e a instância dos homens, tudo fica mais claro. Abandonando-se as explicações metafísicas, o que resta é a política, ou melhor, as palavras da política. E eis que somos remetidos ao dicionário de termos políticos que Rousseau apresenta, no capítulo 6 do primeiro livro do Contrato. "Se consideramos humanamente as coisas", não há contradição alguma em afirmar que, em relação às leis civis, o corpo político instituído no contrato social é soberano $e$ súdito, uma vez que cada um desses termos designa o mesmo objeto, porém, de pontos de vista diferentes: a pessoa pública formada pela união de todos os membros que pactuam recebe o nome de corpo político, "o qual é chamado por seus membros de [...] soberano quando ativo", ao passo que os associados "[...] recebem coletivamente o nome de povo e se chamam, em particular, cidadãos, enquanto participantes da autoridade soberana, e súditos, enquanto submetidos às leis do Estado" (O.C. III, p. 362).

Resta-nos precisar o sentido do termo soberania em função desse simulacro de justiça natural, cujo perigo estaria na possibilidade de tornarse uma soberania ilimitada e, por conta da corrupção dos homens, terminar em despotismo. Robert Derathé, em seu livro Jean-Jacques Rousseau et la science politique de son temps (1950), discute a atitude de Rousseau frente aos jurisconsultos na questão dos limites da soberania. Poderíamos nos indagar, por exemplo, se as leis fundamentais do Estado ou até mesmo a lei natural não seriam fatores que restringem necessariamente a autoridade do soberano. Em sua interpretação, Derathé defende que, para o autor do Contrato, não haveria sentido em falarmos de uma soberania limitada, já que isso acarretaria partilha da soberania, o que estaria em desacordo com a afirmação de que a soberania é indivisível: "Pela mesma razão por que é inalienável, a soberania é indivisível, visto que a vontade ou é geral ou não o é [...]” (O.C. III, p. 369). Da mesma maneira, nas Cartas escritas da montanha (carta VII), o autor afirma acerca do soberano: "[...] ele pode tudo, ou não é nada" (O.C. III, p. 826). Com efeito, para Rousseau, não existe corpo político se o soberano não for soberano em sentido absoluto, como lemos no Contrato (III, 16): “[...] a autoridade suprema não pode modificar-se tanto quanto não pode alienarse; limitá-la equivale a destruí-la” (O.C. III, p. 432). No entanto, Derathé admite que há no texto de Rousseau afirmaçóes que sugerem a possibilidade de uma limitação do poder do soberano, donde se justificaria então não uma distinção rígida entre soberania absoluta e soberania limitada, mas uma outra,

condicionar o segundo ao primeiro, mas considerando-os como perspectivas complementares de um mesmo objeto: a sociedade. 
mais sutil, entre poder absoluto e poder limitado, que aparece em Jurieu e Burlamaqui (cf. DERATHÉ, 2009, p. 490). Refinamento terminológico que, diga-se de passagem, não seria de modo algum descabido, se considerarmos as exigências de precisão no vocabulário de Rousseau. $\mathrm{O}$ comentador explica:

O poder soberano apresenta, portanto, esse duplo caráter, sendo ao mesmo tempo absoluto e limitado. Ele é absoluto porque não existe potência humana que lhe seja superior, e porque seus direitos ou suas prerrogativas não poderiam ser fixados pela constituição do Estado. Mas ele é limitado porque não pode estatuir acerca de um objeto individual. Tal é o paradoxo a que chegamos na teoria da soberania em Rousseau e que desnorteou a maior parte de seus intérpretes. (DERATHÉ, 2009, p. 512).

Polêmicas à parte quanto às possibilidades de interpretação da relação entre soberania e justiça, nos escritos de Rousseau, a sugestão de leitura aqui apresentada partilha com a leitura de Derathé da preocupaçáo acerca do uso extremamente preciso que o autor do Contrato social faz de seu vocabulário político. Mais ainda, no caso de conceitos como o de soberania e o de justiça, que assumiram sentidos os mais diversos ao longo da história da filosofia e que, da maneira como foram apresentados no Contrato social, "desnorteou" os intérpretes do pensador genebrino. Neste artigo, interessou-nos apenas o sentido desses termos no registro de uma obra que, de acordo com o subtítulo, se propunha precisamente fixar os princípios do direito político.

KAWAUCHE, Thomaz. Sovereignty and Justice in Rousseau. Trans/Form/Ação, Marília, v. 36, n. 1, p. 25-36, Jan./Abril, 2013.

\begin{abstract}
This paper discusses the new ideas introduced by Rousseau in relation to the modern notion of sovereignty, of which Bodin is the representative founder. The analysis takes as its subject the relation between sovereignty and civil laws, which is comprehended in terms of the opposition between natural justice and civil justice found in the Social Contract.
\end{abstract}

KEYWORDS: Sovereignty. Justice. Law. Politics. Religion. 


\section{REFERÊNCIAS}

BARROS, A. R. A teoria da soberania de Jean Bodin. São Paulo: Unimarco, 2001.

DERATHÉ, R. Jean-Jacques Rousseau e a ciência política de seu tempo. Trad. Natalia Maruyama. São Paulo: Barcarolla, 2009.

GOLDSCHMIDT, V. Anthropologie et politique: les principes du système de Rousseau. Paris: J. Vrin, 1974.

HOCHART, P. Droit naturel et simulacre. Cahiers pour l'Analyse, Paris, n. 8, 1967.

KAWAUCHE, T. Religiāo e política em Rousseau. São Paulo. 2012. 209 f. Tese (Doutorado em Filosofia) - Faculdade de Filosofia, Letras e Ciências Humanas - Universidade de São Paulo, São Paulo, 2012.

KELSEN, H. O problema da justiça. Trad. João Baptista Machado. São Paulo: Martins Fontes, 1993.

. A ilusão da justiça. Trad. Sergio Tellaroli. São Paulo: Martins Fontes, 1995.

ROUSSEAU, J.-J. Oeuvres Complètes de Jean-Jacques Rousseau. Ed. Bernard Gagnebin e Marcel Raymond. Paris: Gallimard, 1959-1995, 5 v. (Col. "Bibliothèque de la Pléiade").

. Júlia ou A nova Heloísa [1761]. Trad. Fúlvia M. L. Moretto. São Paulo: Hucitec; Campinas: Ed. Unicamp, 1994.

. O contrato social [1762]. Trad. Antonio de Pádua Danesi. 3. ed. São Paulo: Martins Fontes, 2003.

Emílio ou Da educação [1762]. Trad. Roberto Leal Ferreira. 2. ed. São Paulo: Martins Fontes, 1999.

. Cartas escritas da montanha [1764]. Trad. Maria Constança Peres Pissarra e Maria das Graças de Souza. São Paulo: Ed. Unesp; Educ, 2006.

VILLEY, M. A formação do pensamento jurídico moderno. Trad. Claudia Berliner. São Paulo: Martins Fontes, 2005.

Recebido em: 28.05.2012

Aceito em: 30.06.2012 
KAWAUCHE, T. 